\title{
DISCUSSION
}

D. F. PAGE: Is the data obtained from such profile experiments a function of direction of flight over the ice, and if so, how does this affect your interpretation of the data?

R. T. Lowry: We found nothing to indicate preferred ridge orientation. Perhaps Bill Hibler may have more to say about that.

W. D. Hibler III: There have been some studies on ridge orientation, and it has generally been found that on a small scale no preferred orientation is typically shown, and directional effects are not extremely large. On a large scale the nature of sequential deformation of pack ice suggests that anisotropy should be less of a problem. Perhaps more important, mean ridge height is not dependent on the ridging being isotropic and correlation with frequency seems to be fairly consistent.

W. F. WEEKs: When you look at sea ice you commonly see a set of highly oriented leads, and it is easy to assume that the ridges are oriented too. However, this is not necessarily so, as the leads represent the deformation of one instant in time, whereas the ridges have been formed over a period as long as the life of the pack ice, in the course of which the floes have rotated and changed their relative orientation.

G. DE Q. Robin: I understand that SLAR and IR imagery were obtained at the same time as the laser profile. This should give information on any non-isotropic distribution of leads and ridges.

LowRY: None of our sensors showed any preferred orientation of ridges.

S. G. Tooma: Just a thought on the "gliches" you mentioned in the end of scale effects. These might be caused by the laser beam striking the side of a ridge, resulting in a specular reflection away from the laser, causing a momentary loss of signal. The system recycles until the signal is again received, resulting in ice level changes of any height up to the basic full scale you are using.

Lowry: That may well be part of the problem. However, we discussed the problem with the manufacturer of the instrument and were told the errors are inherent in using the "range expander" circuit over rough ice. The device is not yet perfected.

\section{SEA ICE FROM BELOW: SONAR TECHNIQUES}

\author{
By C. S. Clay, T. K. Kan and J. M. Berkson
}

(Geophysical and Polar Research Center, Department of Geology and Geophysics, University of Wisconsin-Madison, Madison, Wisconsin 53706, U.S.A.)

AbSTRACT. Under-ice sonar surveys were carried out in pack-ice fields near Fletcher's Ice Island and at two sites north of Pt. Barrow, Alaska, U.S.A. A narrow-beam scanning sonar was used to measure the location and relative back-scattering of features on the under surface of Arctic sea ice. The $48 \mathrm{kHz}$ sonar had a $\mathrm{I} .5^{\circ}$ by $5^{\circ}{ }^{\circ}$ beam width. Graphic records displaying the range and relative scattering levels were assembled into sonar maps which display location and shape of under-ice features. Two distinct types of back-scattering were found: (I) very high-level back-scattering from well defined under-ice ridges and (2) very 
low back-scattering from areas between ridges. Higher scattering at ridges was probably due to an increase of roughness and tilting of the average plane of the scattering surface. To measure depths of features, the sonar transducer was adjusted to give a wide horizontal beam and a narrow vertical beam. Polar scans were taken at several depths of the transducer to determine depths of ridges. The tops and bottoms of features were compared and the average ratio of peak elevation to keel depth was about $\mathrm{I}: 7$.

Fuller accounts of some of this work have been published elsewhere (Berkson and others, I 973; Clay and Leong, I974; Kan and others, I974).

\section{REFERENCES}

Berkson, J. M., and others. 1973. Mapping the underside of Arctic sea ice by backscattered sound, [by] J. M. Berkson, C. S. Clay, T. K. Kan. Journal of the Acoustical Society of America, Vol. 53, No. 3, p. 777-81.

Clay, C. S., and Leong, W. K. 1974. Acoustic estimates of the topography and roughness spectrum of the sea floor southwest of the Iberian peninsula. (In Hampton, L., ed. Physics of sound in marine sediments. New York,
Plenum Press, p. 424-43.)

Kan, T. K., and others. I 974 . Sonar mapping of the underside of pack ice, [by] T. K. Kan, C. S. Clay and J. M. Berkson. Journal of Geophysical Research, Vol. 79, No. 3, p. 483-88.

\section{DISCUSSION}

W. D. Hibler III: How much error in determining the bottom topography does the finite vertical beam width of the sonar introduce? Is this a major problem?

C. S. Clay: The range of the depth of a ridge which is illuminated increases with range. Correspondingly the upper and lower limits of keel depth spread with increasing range. That is one of the reasons we showed upper and lower limits on the profile. The side lobes are troublesome. They can be reduced by improving the transducer design.

E. R. Pounder: When your transducer was in the vertical position (horizontal fan beam) was any attempt made to change the orientation to scan vertically?

Clay: We held the orientation as nearly horizontal as possible. Poor horizontal resolution was a major problem and accidental tilting of the transducer gave arrivals from a wide range of depths. If we do this again we will use crossed transducers to produce a pencil beam and thus reduce the tilting problem.

I should like to ask Dr Pounder to comment on the lack of back-scattered signal from the ice/water interface at the bottom of the level ice.

Pounder: This is to be expected. Weak echoes would result both from specular reflection and from strong absorption in the skeletal layer of normally growing ice. A submerged ridge would not be likely to have much skeletal layer growth.

W. F. Weeks: I agree. The blocks which form the ridges have only one side which includes the original skeletal layer of the growing ice, the others would be smooth hard surfaces.

Pounder: Furthermore the skeletal layer is probably often destroyed in the process of ridge formation.

E. L. LEwIS: On the other hand an open crystal structure will grow very rapidly in caves and interstices between the blocks, because of the large heat sink resulting from the immersion of the cold blocks during ridge formation. Such structures have been observed by divers and may reduce the reflection of coefficient from parts of the interface. 